\title{
Antiobesity Activity of Flavanoids Isolated from Solanum macrocarpum in Wistar Rats
}

\author{
N. N. Ngwa ${ }^{1}$ and N. M. Nnam ${ }^{2^{*}}$ \\ ${ }^{1}$ Department of Food Science and Technology, Enugu State University of Science and Technology \\ Enugu, Enugu State, Nigeria. \\ ${ }^{2}$ Department of Home Science, Nutrition and Dietetics, University of Nigeria Nsukka, Enugu State, \\ Nigeria.
}

\section{Authors' contributions}

This work was carried out in collaboration between both authors. Author NMN design the study, wrote the protocol and read the first draft of the manuscript. Author NNN managed literature searches, performed and managed the chemical analysis and performed the statistical analysis. Both authors read and approve the final manuscript.

Article Information

DOI: $10.9734 / A R R B / 2019 / v 31$ i230043

Editor(s):

(1) Dr. George Perry, Dean and Professor of Biology, University of Texas at San Antonio, USA.

Reviewers:

(1) Dr. M. V. N. L. Chaitanya, India.

(2) T. V. Odunlade, Obafemi Awolowo University, Nigeria. Complete Peer review History: http://www.sdiarticle3.com/review-history/40244

Original Research Article

Received 07 February 2018

Accepted 26 April 2018

Published 25 March 2019

\section{ABSTRACT}

Aims: To correlate obesity/atherosclerosis with body mass index, serum cholesterol, serum triglyceride, serum low density lipoprotein and serum high density lipoprotein of diet induced obese wistar rats.

Study Design: Department of Home Science, Nutrition and Dietetics (Animal research house) and Department of veterinary science both in University of Nigeria Nsukka. The study was conducted between January to March 2012.

Methodology: Four groups of twenty male Wistar rats were fed a highly palatable diet for 2 weeks to induce obesity resembling mild obesity condition in human population after one week acclimatization period. DIO rats received rat chow and flavonoids extract daily for 6 weeks. Group 1 received rat chow alone; Group 2- $0.05 \%$ of flavonoids extract and rat chow; Group 3- $0.15 \%$ of flavonoid extract and rat chow; and Group $4-0.25 \%$ of flavonoid extract and rat chow. BMI, Total cholesterol, HDL, LDL and Triglyceride were evaluated using standard assay technique. The data 
were statistically analyzed using ANOVA and mean separated using LSD.

Results: Feeding the rats with palatable diet showed increased in BMI (from 0.35-0.40 to 0.600.65), total cholesterol, LDL and triglyceride levels along with decrease in HDL $(p<0.05)$. Consumption of flavonoids resulted in the significant reduction in BMI, LDL, total cholesterol and triglyceride level and exhibit significant elevation in HDL cholesterol compared to the rats fed only rat chow $(p<0.05)$. It was observed that the decrease in BMI, Triglyceride, total cholesterol and LDL cholesterol level of rats fed $0.25 \%$ of flavonoids were significantly different $(p<0.05)$ from those fed $0.15 \%$ and $0.05 \%$ flavonoids.

Conclusions: The results suggest that flavonoids extract from Solanum macranthum has atherogenic effect which can help to reduce obesity.

Keywords: Flavonoids; Solanum macrocarpum; lipid profile; obesity and rats.

\section{INTRODUCTION}

Quite large number of vegetables have long been known and reported to have health protecting properties and uses. Vegetables are important sources of protective substances, which are highly beneficial for the maintenance of good health and prevention of diseases [1,2]. The indigenous knowledge of the health promoting and protecting attributes of vegetables are clearly linked to their nutritional and non- nutrient bioactive properties. Vegetables have long been, and continue to be reported to significantly contribute to the dietary vitamin and mineral intakes of local populations [3]. More recent reports have shown that they also contain nonnutrient bioactive phytochemicals that have been linked to protection against cardiovascular and other degenerative diseases. Phytochemicals are non-nutritive plant chemicals that have protective or disease preventive properties [4]. There are many phytochemicals and each works differently. The feeding habits of people have deteriorated leading to high consumption of fatty foods and refined carbohydrates. The poor feeding habits lead to increased incidence of obesity, diabetes, cardiovascular diseases, high blood pressure and cancer that have been previously rare in the society. These problems are more prominent in urban areas where there is increased preference for a few exotic foods. The food base for the rural population has become narrower, leaving communities more vulnerable to food shortages and nutrient-deficiency diseases. There is low consumption of green leafy vegetables in the diet and these lead to prevalence of micronutrient deficiency. These deficiency diseases lead to retarded physical growth, low intellectual development and a variety of other conditions. The major problem that leads to this study is that there is high prevalence of obesity in the society. The effect of flavonoid levels on obesity induced rats would be ascertained.

\section{MATERIALS AND METHODS}

The study design used was experimental design. The fresh leaves of Solanum macrocarpum was purchased from Ogige market, in Nsukka L.G.A of Enugu State in Nigeria. They were separately plucked and sorted by removing extraneous materials and rinsed with deionized water.

\subsection{Extraction of Flavonoids}

Petrolleum ether, ethanol (aqueous solution: 70 vol.\%) and distilled water was used as the extracting solvents for the extraction of flavonoid $[5]$.

\subsection{Preparation of the Samples}

The blended vegetables was isolated with $(10 \mathrm{~g})$ of essential oil and the extracting solvent was placed in an Erlenmayer flask $(250 \mathrm{~mL})$; the ratio of the vegetables and extracting solvent was 1:10 $w / V$. A series of flaks were immersed into an ultrasonic cleaning bath (Sonic, Ni\{, Serbia) operating at $40 \mathrm{kHz}$ frequency and sonicated at $40 \pm 1^{\circ} \mathrm{C}$ for $20 \mathrm{~min}$, when the maximum concentration of extractable substances in the liquid extracts was achieved [6]. Maceration was performed for 6 hours at room temperature [5]. The liquid extract was separated from the plant material by vacuum filtration, the solvent was evaporated under vacuum, and the extract was dried under vacuum as described. The dry residues were dissolved in methanol $(0.1 \% \mathrm{w} / \mathrm{V})$. The obtained extracts was filtered through filter paper ( $0.45 \mathrm{~m}$; Sartorius, Germany) and used for TLC and HPLC analyses. The identification of flavonoids was performed using standards, which were obtained from the Institute of Botany (Bulgarian Academy of Science, Sofia, Bulgaria). The standards were dissolved in methanol $(0.01$ $\%)$ before use. 


\subsection{Sourcing of Animals}

Twenty male adult rats were purchased from the Department of Veterinary Pathology, University of Nigeria, Nsukka. The animals were divided into 4 groups of 5 rats each on the basis of body weight such that the difference in mean body weight of each group did not exceed $5 g$ [7]. The rats were housed individually in cages equipped to separate urine and feaces in the Department of Home Science, Nutrition and dietetics, University of Nigeria Nsukka animal house. Twenty male adult rats were fed a highly palatable diet for 3 weeks to induce mild obesity. The composition of rodent pelleted chow, are $60 \%$ of energy as carbohydrate, $30 \%$ as protein and $10 \%$ as fat. The palatable diet consisted of $33 \%$ chow, $33 \%$ condensed milk and $7 \%$ sucrose by weight, with the remainder being added water. This provided $65 \%$ of energy as carbohydrate, $19 \%$ as protein and $16 \%$ as fat. This diet was designed to promote weight gain through hyperphagia, without employing major changes in macronutrient composition, compared with normal rat chow. This is a reliable method of inducing weight gain and insulin resistance $[8,9,10]$. Rats were allowed free access to water throughout the study and were maintained on a $12: 12 \mathrm{~h}$ light:dark phase schedule.

At the end of the 2-weeks period, when the palatable diet-treated rats had developed significant weight gain. The extracts were given orally with stringe daily for 6 weeks to the animals. The groups were treated as follows- Group 1 received rat chow alone; Group 2- $(0.05 \%$ ie $100 \mathrm{~g})$ of flavonoids extract; Group 3- $(0.15 \%$ ie $300 \mathrm{~g})$ of flavonoid extract; and Group $4(0.25 \%$ ie $500 \mathrm{~g})$ of flavonoid extract. The weights and length of animals was recorded each day. Daily food intake and extract was also recorded to calculate nutrient intake.

\subsection{Blood Sample Collection and Biochemical Indices Determination}

Blood was collected from the retro-bulba plexus of the medial canthus of the eye of the rats. A nucrocapillary tube was carefully inserted into the canthus of the eye to puncture the retro-bulbar plexus and thus enable outflow of about $2 \mathrm{ml}$ of blood into a clean glass test tube. The blood sample was kept at room temperature for 30 minutes to clot. Afterwards, the test tube containing the clotted blood sample was centrifuged at 3,000 revolutions per minute for ten minutes using a table centrifuge, to enable a complete separation of the serum from the clotted blood. The clear serum supernant was then carefully aspirated with syringe and needle and stored in a clean sample bottle for the clinical chemistry determination. Blood were collected on weeks $0,2,4,6$ and 8 for hematological determinations. The serum was used to determine the cholesterol, LDL, HDL and triglyceride.

\subsection{Hematological Determination}

Enzymatic colorimetric test (CHOD- PAP method) for the in-vitro determination of cholesterol in serum, using Quimica Clinica Applicada (QCA) cholesterol test kit was used to determine serum cholesterol [11].

Dextran sulphate-mg (II) method for the in-vitro determination of HDL-cholesterol in serum, using Quimica Clinica Applicada (QCA) HDL test kit was used to determine HDL [12].

Polyvinyl sulphate method for the in-vitro determination of LDL-cholesterol in serum using Quimica Clinica Applicada (QCA) LDL test kit was used to determine LDL [13].

The composition of the diet is presented in Table 1.

The glycerol-phosphate oxidase method (enzymatic test) for the in-vitro determination of triglycerides in serum, using Quimica Clinica Applicada (QCA) Triglyceride test kit was used to determine triglyceride [14].

The Body mass index was determined as follows:

\section{Instruments}

1. Weighing scale

2. Measuring tape

\section{Method}

1. The length of the rat was determined by measuring the rat with measuring tape from the head to the tail and it was then recorded in centimeters.

2. The weight of the rat was also determined with a weighing scale and the weight recorded in grammes

BMI was calculated by the formula: $\frac{\text { Weight }(\mathrm{g})}{\text { Length }(\mathrm{cm})^{2}}$

The result was expressed as $\mathrm{g} / \mathrm{cm}^{2}$. 
Table 1. Diet composition

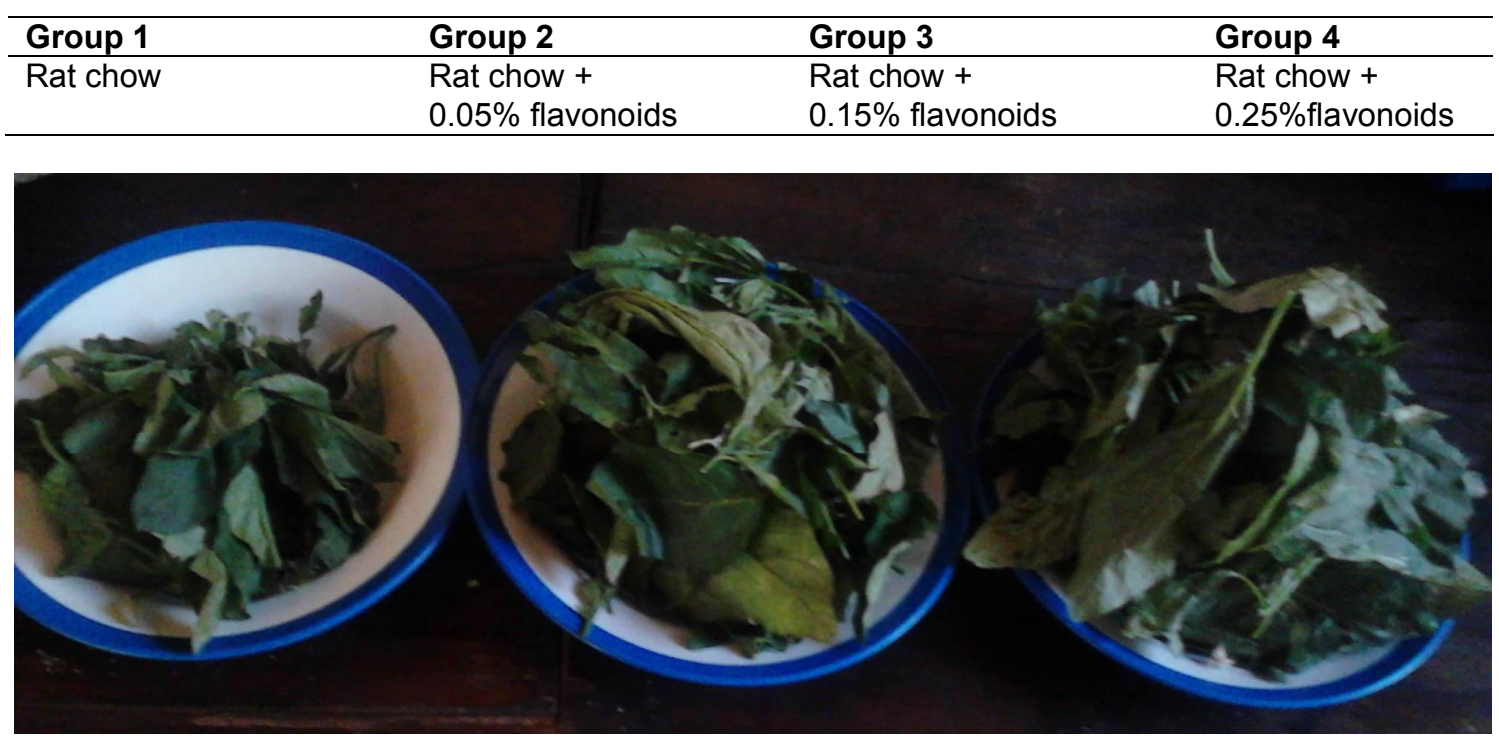

Fig. 1. Shows the different portion sizes $(100 \mathrm{~g}, 300 \mathrm{~g}$ and $500 \mathrm{~g})$ of Solanum macranthum used for rat study

\subsection{Statistical Analysis}

Data collected was subjected to analysis of variance (ANOVA) with Statistical Package for Social Sciences (SPSS) version 22. Means was separated using Least Significance Difference (LSD) and probability judged at $P=.05$.

\section{RESULTS}

Table 2 shows the mean Body Mass Index (BMI) of rats from day 0 -week 8 . At day 0 , which was the first day after acclimatization, the BMI of rats ranged from $0.35-0.40 \mathrm{~g} / \mathrm{cm}^{2}$. At week 2 when obesity was confirmed the BMI level was between $0.60-0.64 \mathrm{~g} / \mathrm{cm}^{2}$. The mean BMI of rats fed rat chow and varied level of flavonoid extract decreased as the week progresses with the group fed $0.25 \%$ flavonoid having the highest decrease.

Table 3 shows the mean cholesterol level of rats from day 0 to week 8 . At day 0 , which was the first day after acclimatization, the total cholesterol of rats ranged from 1.59-1.63 mmol/L. At week 2 when Obesity was confirmed the total cholesterol level was between $2.70-2.74 \mathrm{mmol} / \mathrm{L}$. The mean cholesterol level of rats fed rat chow and varied

Table 2. Effect of flavonoid extract on the BMI of rats

\begin{tabular}{lllll}
\hline Days & $\begin{array}{l}\text { Group 1 } \\
\text { Rat chow alone }\end{array}$ & $\begin{array}{l}\text { Group2 } \\
\text { Rat chow + 0.05\% } \\
\text { Flavoniods }\end{array}$ & $\begin{array}{l}\text { Group3 } \\
\text { Rat chow+ 0.15\% } \\
\text { Flavoniods }\end{array}$ & $\begin{array}{l}\text { Group 4 } \\
\text { Ratchow+ 0.25\% } \\
\text { Flavoniods }\end{array}$ \\
\hline Day 0 & 0.40 & 0.36 & 0.36 & 0.35 \\
Week 2 & 0.61 & 0.64 & 0.65 & 0.60 \\
Week 4 & $0.63(3.28 \%) \uparrow$ & $0.63(1.56 \%) \downarrow$ & $0.62(4.60 \%) \downarrow$ & $0.50(10.00 \%) \downarrow$ \\
Week 6 & $0.63(0 \%)$ & $0.62(1 \%) \downarrow$ & $0.52(16.13 \%) \downarrow$ & $0.46(8.00 \%) \downarrow$ \\
Week 8 & $0.61(3.28 \%) \downarrow$ & $0.54(10.59 \%) \downarrow$ & $0.45(13.46 \%) \downarrow$ & $0.38(17.39 \%) \downarrow$ \\
Total \% $\downarrow \& \uparrow$ & $0 \%$ & $13.15 \% \downarrow$ & $34.19 \% \downarrow$ & $35.39 \% \downarrow$ \\
\hline
\end{tabular}

Value in bracket is the percentage decrease and increase.

Day 0: First day after acclimatization, Week 2: The day obesity was confirmed. Week 4: First test of recovery. Week 6: Second test of recovery. Week 8: Last test of recovery.

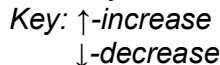


level of flavonoids extract decreases as the week go by with the group that received $0.25 \%$ flavonoid extract having the highest level of increase.

Table 4 shows the mean Low Density Lipoprotein cholesterol (LDL) of rats from day 0 to week 8 . At day 0 , which was the first day after acclimatization, the LDL cholesterol of rats ranged from $0.48-0.50 \mathrm{mmol} / \mathrm{L}$. At week 2 when Obesity was confirmed the LDL cholesterol level was between $0.92-0.99 \mathrm{mmol} / \mathrm{L}$. The mean LDL cholesterol of rats fed rat chow and varied level of flavonoid extract decreased with increase in weeks while the group that received $0.25 \%$ flavonoid extract having the highest level of decrease.

Table 5 shows the mean High Density Lipoprotein cholesterol (HDL) of rats from day 0 to week 8. At day 0 , which was the first day after acclimatization, the HDL of rats ranged from $1.14-1.17 \mathrm{mmol} / \mathrm{L}$. At week 2 when Obesity was confirmed the HDL cholesterol level was between $0.47-0.48 \mathrm{mmol} / \mathrm{L}$. The mean HDL of rats fed varied level of flavonoid extract inceased as the weeks increased with the group fed $0.25 \%$ having the highest level of increase.

Table 6 shows the mean Triglyceride of rats from day 0 to week 8 . At day 0 , which was the first day after acclimatization, the triglyceride level of rats ranged from $0.60-0.66 \mathrm{mmol} / \mathrm{L}$. At week 2 when Obesity was confirmed the triglyceride level was between 1.91-1.96 $\mathrm{mmol} / \mathrm{L}$. The mean triglyceride level of rats fed rat chow and varied level of flavonoid extract varied immensely with the group that received $0.25 \%$ extract having the highest decrease in triglyceride.

\section{Table 3. Effect flavonoid extract on the Cholesterol level of rats}

\begin{tabular}{lllll}
\hline Days & $\begin{array}{l}\text { Group 1 } \\
\text { Rat chow alone }\end{array}$ & $\begin{array}{l}\text { Group2 } \\
\text { Rat chow + 0.05\% } \\
\text { Flavoniods }\end{array}$ & $\begin{array}{l}\text { Group3 } \\
\text { Ratchow+0.15\% } \\
\text { Flavoniods }\end{array}$ & $\begin{array}{l}\text { Group4 } \\
\text { Ratchow+0.25\% } \\
\text { Flavoniods }\end{array}$ \\
\hline Day 0 & 1.60 & 1.63 & 1.59 & 1.61 \\
Week 2 & 2.72 & 2.73 & 2.70 & 2.74 \\
Week 4 & $2.70(0.74 \%) \downarrow$ & $2.61(4.40 \%) \downarrow$ & $2.39(11.48 \%) \downarrow$ & $2.10(23.36 \%) \downarrow$ \\
Week 6 & $2.72(0.74 \%) \uparrow$ & $2.39(12.26 \%) \downarrow$ & $2.14(10.46 \%) \downarrow$ & $1.96(6.67 \%) \downarrow$ \\
Week 8 & $2.73(0.37 \%) \uparrow$ & $2.07(9.61 \%) \downarrow$ & $1.88(12.15 \%) \downarrow$ & $1.64(16.33 \%) \downarrow$ \\
Total \% $\downarrow \& \uparrow$ & $0.37 \% \uparrow$ & $26.27 \% \downarrow$ & $34.09 \% \downarrow$ & $46.36 \% \downarrow$ \\
\hline
\end{tabular}

Value in bracket is the percentage decrease and increase.

Day 0: First day after acclimatization, Week 2: The day obesity was confirmed. Week 4: First test of recovery. Week 6 : Second test of recovery. Week 8: Last test of recovery.

Key: $\uparrow$-increase

$\downarrow$-decrease

Table 4. Effect of flavonoid extract on the Low Density Lipoprotein cholesterol level of rats

\begin{tabular}{lllll}
\hline Days & $\begin{array}{l}\text { Group 1 } \\
\text { Rat chow alone }\end{array}$ & $\begin{array}{l}\text { Group2 } \\
\text { Rat chow+ 0.05\% } \\
\text { Flavoniods }\end{array}$ & $\begin{array}{l}\text { Group3 } \\
\text { Rat chow+ 0.15\% } \\
\text { Flavoniods }\end{array}$ & $\begin{array}{l}\text { Group4 } \\
\text { Ratchow+ 0.25\% } \\
\text { Flavoniods }\end{array}$ \\
\hline Day 0 & 0.50 & 0.50 & 0.48 & 0.50 \\
Week 2 & 0.95 & 0.99 & 0.92 & 0.92 \\
Week 4 & $0.94(1.05 \%) \downarrow$ & $0.86(13.13 \%) \downarrow$ & $0.83(9.78 \%) \downarrow$ & $0.77(16.30 \%) \downarrow$ \\
Week 6 & $0.95(1.06 \%) \uparrow$ & $0.73(1 \%) \downarrow$ & $0.79(3.32 \%) \downarrow$ & $0.67(12.99 \%) \downarrow$ \\
Week 8 & $0.93(2.11 \%) \downarrow$ & $0.72(10.59 \%) \downarrow$ & $0.45(15.18 \%) \downarrow$ & $0.49(26.87 \%) \downarrow$ \\
Total \% $\downarrow \& \uparrow$ & $2.10 \% \downarrow$ & $24.72 \% \downarrow$ & $28.28 \% \downarrow$ & $55.26 \% \downarrow$ \\
\hline \multicolumn{4}{c}{ Value in bracket is the percentage decrease and increase. }
\end{tabular}

Day 0: First day after acclimatization, Week 2: The day obesity was confirmed. Week 4: First test of recovery. Week 6 : Second test of recovery. Week 8: Last test of recovery.

Key: $\uparrow$-increase

$\downarrow$-decrease 
Table 5. Effect of flavonoid on the high density lipoprotein cholesterol level of rats

\begin{tabular}{|c|c|c|c|c|}
\hline Days & $\begin{array}{l}\text { Group } 1 \\
\text { Rat chow alone }\end{array}$ & $\begin{array}{l}\text { Group2 } \\
\text { Rat chow }+0.05 \% \\
\text { Flavoniods }\end{array}$ & $\begin{array}{l}\text { Group3 } \\
\text { Ratchow }+0.15 \% \\
\text { Flavoniods }\end{array}$ & $\begin{array}{l}\text { Group4 } \\
\text { Ratchow }+0.25 \% \\
\text { Flavoniods }\end{array}$ \\
\hline Day 0 & 1.15 & 1.14 & 1.14 & 1.17 \\
\hline Week 2 & 0.48 & 0.48 & 0.47 & 0.47 \\
\hline Week 4 & $0.46(4.17 \%) \downarrow$ & $0.68(41.67 \%) \uparrow$ & $0.67(42.55 \%) \uparrow$ & $0.79(68.09 \%) \uparrow$ \\
\hline Week 6 & $0.48(4.38 \%) \uparrow$ & $0.70(2.94 \%) \uparrow$ & $0.85(26.87 \%) \uparrow$ & $0.93(17.72 \%) \uparrow$ \\
\hline Week 8 & $0.47(2.08 \%) \downarrow$ & $0.96(37.14 \%) \uparrow$ & $1.05(23.53 \%) \uparrow$ & $1.12(20.43 \%) \uparrow$ \\
\hline Total \% $\downarrow \& \uparrow$ & $0.87 \% \downarrow$ & $81.75 \% \uparrow$ & $92.95 \% \uparrow$ & $106.24 \% \uparrow$ \\
\hline
\end{tabular}

Table 6. Effect of flavonoid on the Triglyceride level of rats

\begin{tabular}{lllll}
\hline Days & $\begin{array}{l}\text { Group 1 } \\
\text { Rat chow alone }\end{array}$ & $\begin{array}{l}\text { Group2 } \\
\text { Rat chow + 0.05\% } \\
\text { Flavoniods }\end{array}$ & $\begin{array}{l}\text { Group3 } \\
\text { Rat chow + 0.15\% } \\
\text { Flavoniods }\end{array}$ & $\begin{array}{l}\text { Group4 } \\
\text { Rat chow+ 0.25\% } \\
\text { Flavoniods }\end{array}$ \\
\hline Day 0 & 0.66 & 0.64 & 0.66 & 0.60 \\
Week 2 & 1.91 & 1.95 & 1.91 & 1.96 \\
Week 4 & $1.94(1.57 \%) \uparrow$ & $1.92(1.54 \%) \downarrow$ & $1.65(13.61 \%) \downarrow$ & $1.59(18.88 \%) \downarrow$ \\
Week 6 & $1.90(2.06 \%) \downarrow$ & $1.72(10.42 \%) \downarrow$ & $1.59(3.64 \%) \downarrow$ & $1.26(20.75 \%) \downarrow$ \\
Week 8 & $1.91(0.52 \%) \uparrow$ & $1.60(6.98 \%) \downarrow$ & $1.29(18.88 \%) \downarrow$ & $0.72(42.86 \%) \downarrow$ \\
Total \% $\downarrow \& \uparrow$ & $0.03 \% \uparrow$ & $18.94 \% \downarrow$ & $36.13 \% \downarrow$ & $82.49 \% \downarrow$ \\
\hline
\end{tabular}
Value in bracket is the percentage decrease and increase.

Day 0: First day after acclimatization, Week 2: The day obesity was confirmed. Week 4: First test of recovery. Week 6 : Second test of recovery. Week 8: Last test of recovery.

Key: $\uparrow$-increase $\downarrow$-decrease

\section{DISCUSSION}

\subsection{Body Mass Index (BMI)}

There was an increase in the BMI level of the rats fed fat diet from day 0 which was $0.35-0.40 \mathrm{~g} / \mathrm{cm}^{2}$ to $0.60-0.65 \mathrm{~g} / \mathrm{cm}^{2}$ on week 2 . These were as a result of gradual build up of fatty substances, including cholesterol on the walls of the arteries. This build-up reduces the blood flow to the heart, brain and other tissues which is known as hardening of the arteries [15]. These result to athereosclerosis and obesity. There was a decrease in the BMI level of rats fed varied levels of flavonoids extracts from week 4 to week 8 . The decrease in BMI observed may likely be due to the flavonoids extract that was added to the rat chow. This observation is in line with the findings of Huxley and Neil [16] who opined that high dietary intake of flavonoids from fruits and vegetables as well as from tea and wine, may be associated with a decrease in cardiovascular diseases (CVD) mortality in free living population, where obesity/atherosclerosis is a risk factor. The result showed a higher decrease $(35.39 \%)$ in BMI of the rats fed $0.25 \%$ flavonoids than those fed $0.15 \%, 0.05 \%$ flavonoids and those that received rat chow alone. It was observed that the total percentage decrease in $\mathrm{BMI}$ of rats fed $0.25 \%$ flavonoid extract was $(35.39 \%)$ which is higher than those rats fed $0.15 \%$ flavonoid extract (34.19\%), $0.05 \%$ flavonoid extract $(13.15 \%)$ and those received rat chow alone $(0 \%)$.

\subsection{Cholesterol}

There was an increase in the total cholesterol level of the rats from day $0(1.59-1.63 \mathrm{mmol} / \mathrm{L})$ to $2.70-2.74 \mathrm{mmol} / \mathrm{L}$ at week 2 after consumption of high fat diet. Nordqvist [17] reported that when both blood cholesterol and triglyceride level are high, the risk of developing coronary heart disease rises significantly. There was a decrease in the total cholesterol level of rats fed varied 
levels of flavonoids extract from week 4 to week 8. The decrease in total cholesterol observed may be due to the addition of flavonoids to the rat chow. A Japanese study reported an inverse correlation between flavonoid intake and total plasma cholesterol concentration. Nordqvist [17] also observed that low level of cholesterol aids in the production of bile, which converts sunshine to vitamin D. Bile is also important for the metabolism of fat soluble vitamins, including vitamin $A, D, E$ and $K$. The result showed higher decrease in cholesterol level of rats fed $0.25 \%$ flavonoids $(46.36 \%)$ than the other three experimental groups. It was observed that the total percentage decrease in cholesterol levels of rats fed $0.25 \%$ flavonoid extract was $(46.36 \%)$ which is higher than those of rats fed $0.15 \%$ flavonoid extract (34.09\%), $0.05 \%$ flavonoid extract $(26.27 \%)$ and those received rat chow alone had $0.37 \%$ increase. The result is in line with the findings of Huxley and Neil [16] who opined that high dietary intake of flavonoids from fruits and vegetables as well as from tea and wine, may be associated with a decrease in CVD mortality in free living population which obesity/atherosclerosis is a risk factor.

\subsection{Low Density Lipoprotein (LDL)}

There was an increase in the LDL cholesterol level of the rats from day $0(0.48-0.50 \mathrm{mmol} / \mathrm{L})$ to $0.92-0.99 \mathrm{mmol} / \mathrm{L}$ at week 2 after consumption of high fat diet. The decrease in the LDL cholesterol level of rats fed varied levels of flavonoids extract from week 4 to week 8 is of interest. The decrease in the level of LDL cholesterol level may be due to the consumption of flavonoids, which was added to the rat chow. Middleton, Kandaswani and Theoharides [18] observed that elevated plasma low density lipoprotein (LDL) cholesterol concentration is a primary risk factor for the development of atherosclerosis and coronary artery diseases. Nordqvist [17] observed that high LDL cholesterol increased the risk of arterial disease. Hertog, Fesich and Hollman [19] observed that flavonoids seem to suppress LDL cholesterol oxidation and inflammatory progression in the artery wall. The result showed a higher decrease in LDL cholesterol level of rats fed $0.25 \%$ flavonoids than the other three experimental groups. It was observed that the total percentage decrease in LDL of rats fed $0.25 \%$ flavonoid extract was $(55.26 \%)$ which was higher than those of rats fed $0.15 \%$ flavonoid extract $(28.28 \%), \quad 0.05 \%$ flavonoid extract $(24.72 \%)$ and those that received rat chow alone $(2.10 \%)$. The results were in line with the findings of Huxley and Neil [16] who opined that high dietary intake of flavonoids from fruits and vegetables as well as from tea and wine may be associated with a decrease in CVD mortality in free living population where obesity/atherosclerosis is a risk factor.

\subsection{High Density Lipoprotein (HDL)}

There was a decrease in the total HDL cholesterol level of the rats from day 0 (1.14$1.17 \mathrm{mmol} / \mathrm{L})$ to $0.47-0.48 \mathrm{mmol} / \mathrm{L}$ at week 2 after consumption of high fat diet. There was an increase in the HDL cholesterol level of rats fed varied levels of flavonids extract from week 4 to week 8. The increase in the level of HDL cholesterol level may be due to the addition of flavonoids to the rat chow. Nordqvist [17] noted that HDL cholesterol takes cholesterol away from the cells. Sonoyama et al. [20] reported that plasma cholesterol concentration was significantly lowered in rats fed beet fibre and this difference was due mainly to a higher HDL cholesterol concentration. The result showed higher increase in HDL cholesterol level of rats fed $0.25 \%$ flavonoids than those fed $0.15 \%, 0.05$ $\%$ flavonoids extract and rat chow alone. It was observed that the total percentage increase in HDL of rats fed $0.25 \%$ flavonoid extract was $(106.24 \%)$ which was higher than those of rats fed $0.15 \%$ flavonoid extract $(92.95 \%), 0.05 \%$ flavonoid extract $(81.75 \%)$ and those that received rat chow alone had $0.87 \%$ decrease. Dauchet, Amonyel, Herberg and Dallongeville [21] observed that the risk of CVD was dose dependent and decreased by $4 \%$ for each additional portion per day of vegetables and by $7 \%$ for fruits consumption.

\subsection{Triglycerides}

There was an increase in the triglyceride level of the rats from day $0(0.60-0.66 \mathrm{mmol} / \mathrm{L})$ to $1.80-$ $2.20 \mathrm{mmol} / \mathrm{L}$ at week 2 after consumption of high fat diet. There was a decrease in the triglyceride level of rats fed varied levels of flavonoids extract from week 4 to week 8 . The decrease in the level of triglyceride level was probably due to the addition of flavonoids to the rat chow. Nelson, Cox and Lehninger [22] observed that in human body, high triglycerides in the blood stream have been linked to atherosclerosis and by extension, the risk of heart disease and stroke. The risk can partly be accounted for by a strong inverse relationship between triglyceride and $\mathrm{HDL}$ cholesterol level [22]. The result showed a higher 
decrease in triglceride level of rats fed $0.25 \%$ flavonoids than those fed $0.15 \%, 0.05 \%$ flavonoids extract and rat chow alone. It was observed that the total percentage decrease in triglyceride of rats fed $0.25 \%$ flavonoid extract was $82.49 \%$ which was higher than those of rats fed $0.15 \%$ flavonoid extract (36.13\%), 0.05\% flavonoid extract (18.94\%) and those that received rat chow alone had $0.03 \%$ increase.

\section{CONCLUSION}

This study showed that flavonoid extract from Solanum macranthum significantly reduced the lipid profile (Body mass index (BMI), low density lipoprotein (LDL), cholesterol and triglyceride) of diet induced obesed rats. Consumption of $500 \mathrm{~g}$ portion size of Solanum macranthum daily is of great importance since reduction of obesity and atherosclerosis is dose depenedent. Consumption of small quantity of vegetables will be of little or no benefit to the body. These extract however caused significant decreases in BMI, LDL, Total cholesterol and Triglyceride levels with increase in HDL cholesterol of the rats. The result suggests a great atherogenic potential of Solanum macranthum.

\section{ETHICAL APPROVAL}

As per international standard or university standard written ethical approval has been collected and preserved by the authors.

\section{COMPETING INTERESTS}

Authors have declared that no competing interests exist.

\section{REFERENCES}

1. Sheela K, Kamal G, Nath D, Vijayalakshmi GM, Yankanchi, Roopa BP. Proximate composition of underutilized green leafy vegetables in Southern Karnataka. Journal of Human Ecology. 2004;15(3):227-229.

2. Nnamani CV, Oselebe HO, Okporie EO. Ethnobotany of Indigenous Leafy Vegetables of Izzi Clan, in Ebonyi State, Nigeria. In: Proceeding of 20th Annual National Conference of Biotechnology Society of Nigeria. Abakaliki, November 14th -17th, 111-114; 2007.

3. Oboh G, Akindahunsi AA. Change in ascorbic acid, total phenol and antioxidant activity of sun-dried commonly consumed green leafy vegetables in Nigeria. Nutrition. \& Health. 2004;18:29-36.

4. Velickovic D, Nikolova MS, Ivaneva J. Stojanovic, \& Veljkovic, V. (2004) XXVI.

5. Symposium for Medicinal and Aromatic Plants, VIII Days of Medicinal Plants (Bajina Bacta, Serbia), Book of Abstracts 92.

6. Velickovic D, Nikolova MS, Ivaneva J. Stojanovic, Veljkovic V. XXVI Symposium for Medicinal and Aromatic Plants, VIII Days of Medicinal Plants (Bajina Bacta, Serbia), Book of Abstracts. 2006;92.

7. AOAC. Association of Official Analytical Chemist. Official methods of Analysis, Washington, D.C; 1995.

8. Widdowson PS, Upton R, Buckingham R, Arch J, Williams G. Inhibition of food response to intracerebroventricular injection of leptin is attenuated in rats with diet-induced obesity. Diabetes. 1996;46: 1782-1785. [PubMed]

9. Wilding JPH, Gilbey SG, Mannan M, Aslam $\mathrm{N}$, Ghatei MA, Bloom SR. Increased neuropeptide $Y$ content in individual hypothalamic nuclei, but not neuropeptide mRNA, in diet-induced obesity in rats. J. Endocrinol. 1992;132:299-304. [PubMed]

10. Pickavance LC. Therapeutic index for rosigitazone in dietary obese rat: separation of efficacy and haemodilution. British Journal of Pharmacology (www.ncbi.nlm.nih.gov); 1996.

11. Allain CC, Poon LS, Chan CS, Richmond W, Fu PC. Enzymatic determination of total cholesterol. Clinical Chemistry. 1974;20(4): 470-475.

12. Albers JJ, Warnick GR, Cheng MC. Quantification of high density lipoproteins. Lipids. 1978;13:926-932.

13. Assman G, Jab HU, Hohnert U. LDLcholesterol determination in blood following precipitation of LDL with polyvinyl sulfate. Clinical Chemistry. Acta. 1984;140:77-83.

14. Jacobs NJ, VanDemark PJ. Architectural Biochemistry. Biophysics. 1960;88:250255.

15. Patel JM. A review of potential health benefits of flavonoids. Lethbridge Undergraduate Research Journal. 2008; $3(2)$.

16. Huxley RR, Neil HA. The relation between dietary flavonol intake and coronary heart disease mortality: A meta-analysis of prospective cohort studies. European Journal of Clinical Nutrition. 2003;57:9048. 
17. Nordqvist C. High density vs low-density lipoprotein cholesterol as the risk factor for coronary artery; 2003 (www.ncbi. nlm.nih.gov).

18. Middleton E, Kandaswami C, Theoharides TC. The effects of plant flavonoids on mammalian cells: Implications for inflammation, heart disease, and cancer. Pharmacology Review. 2000;52:673-751.

19. Hertog MGL, Hollman PCH, van de Putte B. Content of potentially anticarcinogenic flavonoids of tea infusions, wines, and fruit juices. Journal of Agricultural Food Chemistry. 1993;41:1242-1246.
20. Sonoyama K, Nishikawa H, Kiriyama S, Niki R. Apolipoprotein mRNA in liver and intestine of rats is affected by dietary beet fiber or cholestyramine. Journal of Nutrition. 1995;125:13-19.

21. Dauchet L, Amouyel P, Hercberg S, Dallongeville J. Fruit and vegetable consumption and risk of coronary heart disease: A meta-analysis of cohort studies. Journal of Nutrition. 2006;136:2588-93.

22. Nelson DL, Cox MM. Lehninger, principles of biochemistry" 3rd Ed. Worth Publishing: New York; 2000. ISBN 1-57259-153-6.

(c) 2019 Ngwa and Nnam; This is an Open Access article distributed under the terms of the Creative Commons Attribution License (http://creativecommons.org/licenses/by/4.0), which permits unrestricted use, distribution, and reproduction in any medium, provided the original work is properly cited.

\section{Peer-review history:}

The peer review history for this paper can be accessed here: http://www.sdiarticle3.com/review-history/40244 